\title{
MANAGEMENT OF ENDOCRINE DISEASE Critical review of the evidence underlying management of glucocorticoid-induced hyperglycaemia
}

\author{
Anjana Radhakutty 1,2,3 and Morton G Burt ${ }^{1,2}$ \\ ${ }^{1}$ College of Medicine and Public Health, Flinders University, Adelaide, South Australia, Australia, ${ }^{2}$ Southern Adelaide \\ Diabetes and Endocrine Services, Flinders Medical Centre, Adelaide, South Australia, Australia, and ${ }^{3}$ Department of \\ Diabetes and Endocrinology, Lyell Mc Ewin Hospital, Adelaide, South Australia, Australia
}

\author{
Correspondence \\ should be addressed \\ to M G Burt \\ Email \\ morton.burt@sa.gov.au
}

\begin{abstract}
Glucocorticoids are frequently prescribed to patients with a wide range of inflammatory and autoimmune diseases. The semi-synthetic glucocorticoid prednisolone is most commonly prescribed and in two main patterns. Prednisolone is prescribed short term at medium-high doses to treat an acute inflammatory illness or long term at lower doses to attenuate chronic inflammatory disease progression. In hospitalized patients with acute prednisolone-induced hyperglycaemia, there is a distinct circadian pattern of glucose elevation, which occurs predominantly in the afternoon and evening. As a morning dose of isophane insulin has a pharmacokinetic pattern that matches this pattern of glucose elevation, treatment comprising a basal dose of morning isophane insulin in combination with short-acting insulin boluses is generally recommended. However, evidence is lacking that isophane-based basal bolus insulin is more efficacious than other insulin regimens. In outpatients, low-dose prednisolone causes a small increase in post glucose-load glucose concentration but no change in overall glycaemic control as measured by glycosylated haemoglobin. If treatment is indicated, metformin has been shown to be effective and may attenuate other adverse effects of long-term prednisolone therapy. Further studies are necessary in order to identify factors underlying the variability in response to insulin therapy and clinical benefits of treatment in hospitalized patients with prednisoloneinduced hyperglycaemia. In outpatients prescribed low-dose prednisolone, the cardiovascular risk associated with postprandial hyperglycaemia and efficacy of hypoglycaemic therapies should be evaluated in future randomized clinical trials.

\section{Invited author's profile}

Associate Professor Morton G Burt is an Endocrinologist working within the Southern Adelaide Diabetes and Endocrine Service, Flinders Medical Centre and Associate Professor, FlindersUniversity in Adelaide, Australia. Associate Professor Burt completed a PhD at the Garvan Institute of Medical Research, Sydney, Australia investigating the effect of glucocorticoids on protein metabolism. Currently, his primary research interests are the effects of glucocorticoid excess on carbohydrate metabolism and cardiovascular risk and management of inpatient hyperglycaemia.

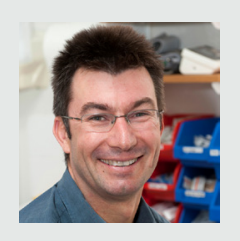




\section{Introduction}

The seminal publication in 1949 by Hench et al. reporting that glucocorticoids produced a clinical benefit in patients with rheumatoid arthritis changed the outlook for patients with an inflammatory illness (1). One year later, Hench was awarded the Nobel Prize in Physiology or Medicine along with Edward Jenner and Thadeus Reichstein, who first identified the endogenous glucocorticoid cortisol (2). Glucocorticoids are now recognized to be potent antiinflammatory agents that modulate many components of the inflammatory cascade via genomic and nongenomic mechanisms (3). Despite the development of a range of other pharmaceutical and biologic agents that reduce inflammation, glucocorticoids remain a critical part of the therapeutic armamentarium for a wide range of inflammatory and autoimmune diseases and the prevalence of glucocorticoid use is increasing (4).

Early studies reported glucocorticoid therapy can increase blood glucose concentration (5). However, almost 70 years after their first use the indications for treatment of glucocorticoid-induced hyperglycaemia and optimum therapeutic approach remain unclear. Management of this large group of patients is dependent on extrapolated data from other clinical scenarios combined with an understanding of the pharmacokinetics and pharmacodynamics of glucocorticoids and hypoglycaemic agents.

Glucocorticoids are most commonly prescribed as the semi-synthetic formulation prednisolone (or prednisone in some parts of the world), which is usually administered as a single morning dose $(6,7,8)$. Prednisolone therapy is usually prescribed in two main patterns. It can be prescribed short-term in medium-high doses to treat an acute inflammatory illness such as an exacerbation of obstructive lung disease, often in the hospital setting. Prednisolone is also prescribed long term at lower doses, usually less than $10 \mathrm{mg} /$ day, to attenuate chronic inflammatory disease progression $(6,9)$. Similar glucocorticoid doses are also prescribed to prevent rejection after solid organ transplant and in patients needing glucocorticoid replacement therapy.

This manuscript will first briefly discuss the metabolic pathways that are affected by glucocorticoids and then review the indications for and efficacy and safety of treatment for hyperglycaemia in (1) hospitalized patients on moderate to high dose prednisolone and (2) outpatients on long-term therapy with lower prednisolone doses. Other clinical scenarios will also be briefly considered. We selected studies to cite in this manuscript after searching PubMed for glucocorticoids AND diabetes, glucocorticoids
AND hyperglycaemia and glucocorticoids AND a range of glucose-lowering therapies. Additional articles were selected from our knowledge of the topic. We have tried to limit recommendations to those supported by the literature or to articulate where evidence is lacking.

\section{Mechanisms of glucocorticoid-induced hyperglycaemia}

Glucocorticoid-induced hyperglycaemia is the result of impairment of multiple pathways affecting carbohydrate metabolism. Glucocorticoids induce peripheral insulin resistance, which predominantly reflects insulin action in skeletal muscle $(10,11)$. At higher doses glucocorticoids impair oxidative and non-oxidative glucose disposal, whereas in patients on long-term low-dose prednisolone non-oxidative glucose disposal is predominantly reduced $(11,12)$. Glucocorticoids reduce glycogen synthase activity in skeletal muscle, which will contribute to a reduction in peripheral non-oxidative glucose disposal (13).

Other aspects of carbohydrate metabolism are also affected. Glucocorticoids cause hepatic insulin resistance resulting in increased hepatic glucose output, even during long-term low-dose prednisolone therapy $(10,12,14)$. Acutely glucocorticoids also reduce insulin secretion, but insulin secretion is not reduced in patients on long-term low-dose prednisolone $(12,15,16)$. An acute reduction in incretin-induced insulin secretion is likely to contribute to the observed reduction in insulin secretion with glucocorticoids (17).

\section{Acute moderate-to-high-dose prednisolone therapy}

\section{How common is prednisolone-induced hyperglycaemia?}

Glucocorticoids are prescribed short term in moderateto-high doses to treat exacerbations of a range of inflammatory illnesses including those of the lungs, gastrointestinal tract, nervous system, joints, kidneys and skin. Glucocorticoids cause a greater increase in blood glucose levels in patients with known diabetes $(18,19)$. However, $50-70 \%$ of hospitalized patients without known diabetes prescribed moderate-to-high glucocorticoid doses also develop hyperglycaemia $(8,18$, 20). Differences in patient populations will contribute to variability in the prevalence of hyperglycaemia. In 
hospitalized patients known diabetes, a longer duration of glucocorticoid therapy, an elevated C-reactive protein and older age have been associated with a greater prevalence and/or severity of hyperglycaemia $(8,18,20)$. Abdominal adiposity and a family history of diabetes have also been associated with an increased prevalence of glucocorticoidinduced hyperglycaemia $(21,22)$. Higher glucocorticoid doses cause a greater degree of insulin resistance and are associated with a greater need for hypoglycaemic therapy and will also influence the prevalence of hyperglycaemia $(23,24)$.

\section{Is treating hyperglycaemia during acute prednisolone therapy important?}

In hospitalized patients, the primary aim of treatment of hyperglycaemia is to prevent any potential excess in morbidity and mortality secondary to glucose elevation during treatment and recovery from an acute illness or surgical procedure (25). There is little direct evidence that treating prednisolone-induced hyperglycaemia reduces morbidity or mortality. In patients with pneumonia treated with prednisone, differences in glucose concentration were not associated with time to clinical stability (26). However, glucocorticoids are a common cause of new hyperglycaemia in hospitalized patients, and new hyperglycaemia is associated with a much greater risk of mortality than chronic hyperglycaemia (27). Moreover, there is evidence that treating inpatient hyperglycaemia reduces morbidity in other clinical scenarios (28). Current guidelines recommend screening all hospitalized patients prescribed glucocorticoids for hyperglycaemia by point of care blood glucose level monitoring for at least $48 \mathrm{~h}$ and treatment of those with hyperglycaemia (25).

The glucose threshold at which hypoglycaemic treatment should be started is uncertain. Continuous glucose monitoring of non-diabetic hospitalized patients taking prednisolone demonstrates that although in many patients glucose increases to above $10 \mathrm{mmol} / \mathrm{L}$, it usually stays above this threshold for only a few hours and mean glucose in these patients was $7.7 \mathrm{mmol} / \mathrm{L}$ (18). Although there are plausible mechanisms by which short-term hyperglycaemia might increase morbidity and mortality, such as inducing endothelial dysfunction and oxidative stress (29), data on major clinical endpoints are lacking. In our study, the inclusion criteria for hypoglycaemic therapy were one blood glucose level above $15 \mathrm{mmol} / \mathrm{L}$ or two blood glucose levels above $10 \mathrm{mmol} / \mathrm{L}$ within $24 \mathrm{~h}$, to ensure subjects had either marked or sustained hyperglycaemia (30).

\section{What therapy should be used to treat acute prednisolone-induced hyperglycaemia?}

As the aim of glucose-lowering therapy in hospitalized patients is to rapidly control glucose elevations to improve patient outcomes, the Endocrine Society Clinical Practice Guidelines recommend that glucocorticoid-induced hyperglycaemia in hospital should be treated with subcutaneous basal bolus insulin or a continuous insulin infusion if there is severe or persistent hyperglycaemia (25). The rapid onset of action, flexibility in dosing and lack of dose ceiling makes subcutaneous basal bolus insulin a good choice in patients with acute hyperglycaemia on glucocorticoids. As many patients have elevated glucose levels on a standard hospital basal bolus insulin protocol, a specific protocol for prednisolone-induced hyperglycaemia may be required (31). Similar to results in other hyperglycaemic patients, an insulin sliding scale is not recommended as it is less effective than subcutaneous basal bolus insulin in glucocorticoid-treated patients $(32,33,34)$.

There are limited data on the use of other hypoglycaemic agents in the management of glucocorticoid-induced hyperglycaemia in the hospital setting. It has been recommended that these agents be discontinued in hospital when initiating insulin therapy (25), but this decision should be individualized. The efficacy of other hypoglycaemic agents will be discussed in the section on long-term glucocorticoid treatment.

\section{Pharmacokinetics of insulin therapy for prednisolone-induced hyperglycaemia}

Studies characterizing the circadian pattern of glucose elevation induced by prednisolone potentially inform the pharmacokinetic profile of insulin therapy for prednisolone-induced hyperglycaemia $(18,19)$. Following an oral morning dose of prednisolone the glucose concentration peaks $8 \mathrm{~h}$ later at about 16:00 h (Fig. 1) (18). This pattern is similar to the timing of prednisolone's peak anti-inflammatory action (35). In patients without known diabetes glucose returns to normal by midnight with little effect on overnight glucose concentration (18). In patients with diabetes, glucose elevations are greater, but the circadian pattern of hyperglycaemia is similar $(18,19)$.

These studies support recommendations to use insulin isophane alone or in combination with short-acting insulin to treat glucocorticoid-induced hyperglycaemia. When administered as a single morning dose, insulin isophane's onset of action, peak effect and duration 


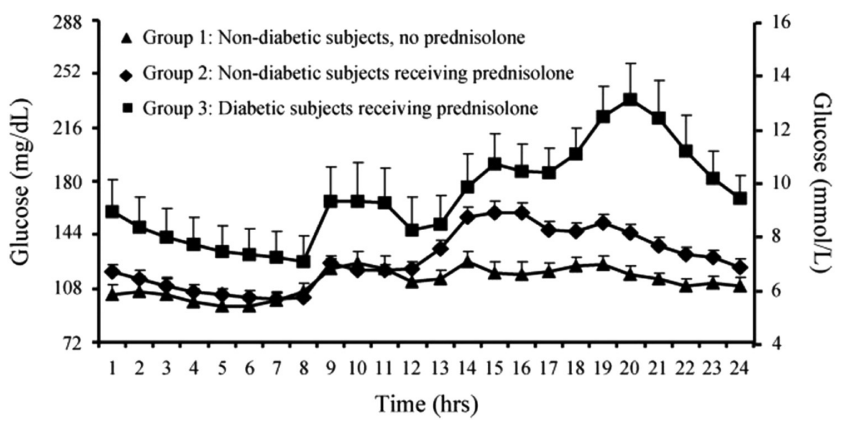

\section{Figure 1}

Average hourly interstitial glucose concentration in 13 controls with COPD without known diabetes admitted for other indications and not treated with glucocorticoids (Group 1), 40 patients without known diabetes admitted to hospital with a COPD exacerbation and treated acutely with prednisolone (Group 2) and 7 diabetic COPD patients treated with prednisolone (Group 3). Values represent mean \pm standard error. The $x$ axis signifies time of day in military time. (From reference (18) with permission.)

of action closely match the pattern of prednisoloneinduced hyperglycaemia (36). Thus, insulin isophane has the potential to better treat daytime hyperglycaemia and avoid overnight hypoglycaemia arising from longeracting basal insulin preparations.

However, the small numbers of clinical studies performed have not conclusively demonstrated a benefit of insulin isophane in patients with glucocorticoidinduced hyperglycaemia (Table 1). A retrospective study comparing insulin isophane and insulin glargine as the basal insulin in hospitalized patients with hyperglycaemia on prednisone was promising as isophane-treated patients required $20 \%$ less insulin to achieve the same degree of glycaemic control (37). Another study reported prescribing additional isophane insulin as well as the standard hospital subcutaneous basal bolus insulin regimen resulted in a lower mean glucose concentration on the third day of insulin therapy (38). However, isophane-treated patients' daily insulin dose was 16\% higher than controls in this study and optimal assessment of the effect of different pharmacokinetic insulin profiles per se requires matching of insulin doses.

Two complementary randomized controlled studies have compared matched doses of isophane-based and glargine-based basal bolus insulin in patients on glucocorticoids $(30,39)$. In both studies, $50 \%$ of the daily dose was administered as basal insulin and 50\% as short-acting insulin with meals $(30,39)$. Ruiz de Adana et al. reported that in patients with type 2 diabetes and respiratory disease treated with methylprednisolone or deflazacort, there was no significant difference in glucose control between patients randomized to glargine- or isophane-based basal bolus insulin (39). Similarly, we reported no difference in mean glucose or hypoglycaemia in patients with hyperglycaemia with or without known diabetes while taking short-term prednisolone who were randomized to insulin glargine and insulin aspart vs insulin isophane and insulin aspart (30).

We analysed our study to understand why there was no significant difference between isophane- and glarginetreated patients (30). Firstly, despite body weight-based insulin dosing, there was marked variability in the therapeutic response in both treatment groups. Figure 2 shows that there were patients on both insulin regimens who were within a target glucose range of $4-10 \mathrm{mmol} / \mathrm{L}$ nearly all the time and other patients who were almost always outside the target range. BMI, mean glucose on the day before starting insulin and prior insulin treatment were independent predictors of response to insulin, but only explained $48 \%$ of the variability in time outside the target glucose range. Secondly, patients were usually discharged rapidly from the hospital and insulin pharmacokinetics is likely to be more important when the insulin doses have been optimized.

Table 1 Studies comparing isophane insulin-based regimens to other therapeutic regimens in patients on glucocorticoids.

\begin{tabular}{|c|c|c|c|}
\hline Study & Study design & Glucocorticoid & Isophane group \\
\hline 37) & Retrospective & Prednisone & $\begin{array}{l}\text { Isophane and } \\
\text { short-acting }\end{array}$ \\
\hline (38) & Prospective RCT & Any & $\begin{array}{l}\text { Isophane, } \\
\text { glargine and } \\
\text { lispro }\end{array}$ \\
\hline (39) & Prospective RCT & $\begin{array}{l}\text { Methylprednisolone or } \\
\text { deflazacort }\end{array}$ & $\begin{array}{l}\text { Isophane and } \\
\text { glulisine }\end{array}$ \\
\hline (30) & Prospective RCT & Prednisolone & $\begin{array}{l}\text { Isophane and } \\
\text { aspart }\end{array}$ \\
\hline
\end{tabular}

\begin{tabular}{lll}
\hline Comparator & & Results/comments \\
\cline { 1 - 1 } $\begin{array}{c}\text { Glargine and } \\
\text { short-acting }\end{array}$ & & No difference in glycaemic control \\
Glargine and & & Isophane group used $20 \%$ less insulin \\
lispro & & Isophane group used lower BGL on Day 3 \\
& & \\
Glargine and & No difference in glycaemic control \\
glulisine & Groups matched for insulin dose \\
Glargine and & No difference in glycaemic control \\
aspart & Groups matched for insulin dose
\end{tabular}

BGL, blood glucose level; RCT, randomized controlled trial. 
What insulin dose should be prescribed for prednisolone-induced hyperglycaemia in hospital?

The Endocrine Society Clinical Practice Guidelines recommend a starting daily insulin dose of $0.3-0.5$ units $/ \mathrm{kg}$ body weight in hospitalized patients with hyperglycaemia on glucocorticoids (25). Others have recommended a single daily dose of isophane based on weight and prednisone dose, with the daily insulin dose increased by 0.1 units/kg for every $10 \mathrm{mg}$ of prednisone prescribed, up to a maximum of 0.4 units $/ \mathrm{kg}$ (36). However, the evidence for these recommendations is limited. In our study insulin-naïve patients were prescribed a starting daily insulin dose of 0.5 units $/ \mathrm{kg}$ plus supplemental insulin for hyperglycaemia, resulting in a daily insulin dose of more than 0.6 units $/ \mathrm{kg}$ (30). There were no episodes of severe hypoglycaemia and glucose measured with a continuous glucose monitoring system was below $4 \mathrm{mmol} / \mathrm{L}$ for only $2 \%$ of the day. Others have also reported that the risk of hypoglycaemia with similar insulin doses is low in this patient group (39). We recommend that in hospitalized patients, where the aim is rapid glycaemic control, most patients who have not previously been on insulin should be prescribed an initial daily dose of 0.5 units $/ \mathrm{kg}$. Patients at increased risk of hypoglycaemia should be started on a lower daily insulin dose, such as $0.3-0.4$ units $/ \mathrm{kg}$.

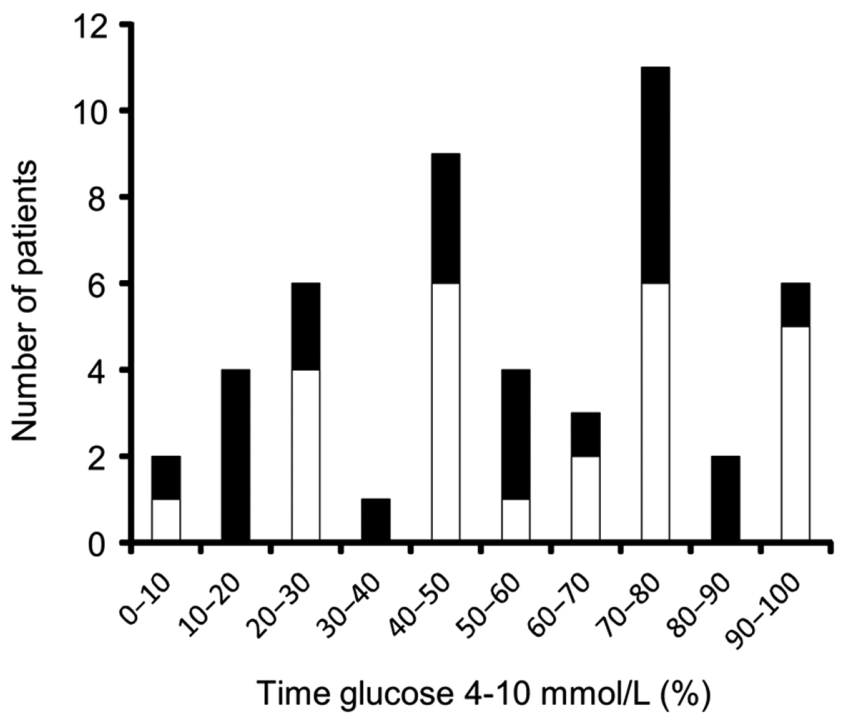

Figure 2

The percentage of time patients with prednisolone-induced hyperglycaemia randomized to isophane and aspart (white bars) or glargine and aspart (black bars) insulin regimens achieved target glycaemia $(4-10 \mathrm{mmol} / \mathrm{L})$ on Day 1 of treatment. (From reference (30) with permission.)
Insulin dosing requirements in patients with type 2 diabetes who are already taking insulin are even less studied. In our study, we increased daily insulin dose by $30 \%$ or to 0.5 units $/ \mathrm{kg}$, whichever was greater (30). However, during continuous glucose monitoring, the blood glucose level was above $10 \mathrm{mmol} / \mathrm{L}$ for $70 \%$ of the day. Therefore, most patients with similar clinical characteristics to those in our study will require $>30 \%$ increase in insulin to achieve good glycaemic control.

Finally, patients with glucocorticoid-induced hyperglycaemia that do not initially reach treatment targets require greater increases in the insulin dose than in other clinical scenarios. Despite a 19\% increase in daily insulin dose over $48 \mathrm{~h}$, we found no significant change in glycaemic control. In contrast, an increase in mean daily insulin dose of $48 \%$ over the same time period did reduce mean daily blood glucose level (38). Supplemental insulin doses should also be higher in glucocorticoid-treated patients, consistent with guidelines for insulin-resistant patients (25).

\section{Hospital discharge planning}

It is critical that hospitalized patients with prednisoloneinduced hyperglycaemia are given advice regarding reducing insulin doses as prednisolone is tapered or stopped to prevent hypoglycaemia. If high-dose prednisolone is stopped abruptly, and assuming glycaemic control has previously been good, patients should be advised to return to their usual treatment before starting prednisolone. Although supporting evidence is lacking, it has been recommended that a reduction in prednisolone dose should be associated with a proportionate reduction in insulin doses (36).

\section{Outpatients with high-dose prednisolone-induced hyperglycaemia}

There are limited data informing how to manage outpatients with hyperglycaemia on high-dose prednisolone. However, if insulin is prescribed, practically once-daily treatment with a morning dose of isophane insulin is easier for patients to learn to administer than multiple daily insulin injections. We recommend starting with a lower daily insulin dose of $0.3-0.4$ units $/ \mathrm{kg}$ as the support to manage severe hypoglycaemia in the community might not be as prompt as in hospital. The efficacy of other hypoglycaemic agents will be reviewed in the section on chronic prednisolone use. 


\section{Other glucocorticoid regimens}

Yates et al. reported that dividing prednisolone into two daily doses attenuates the daytime peak in glucose and reduced mean daily glucose, but patients have a higher glucose concentration overnight (40). Consequently patients on twice-daily prednisolone with hyperglycaemia are probably best treated with a longer-acting basal insulin with a flatter insulin profile, such as glargine or detemir, alone or in combination with a short-acting insulin if there are postprandial glucose elevations. Dexamethasone has a longer serum half-life and duration of action than prednisolone, but whether it causes a glucose peak is not clearly documented. However, based on the current understanding of its pharmacokinetics, dexamethasoneinduced hyperglycaemia should also be treated with a longer-acting basal insulin. The doses of insulin required for patients treated with dexamethasone (and other glucocorticoids) have not been well studied, but should take into account its greater glucocorticoid potency compared to prednisolone (41).

\section{Summary}

The aim of treating prednisolone-induced hyperglycaemia in hospitalized patients is to rapidly control glucose elevations to potentially reduce associated morbidity and mortality. Based on the circadian pattern of glucose elevation induced by prednisolone, hyperglycaemia should be treated with isophane insulin alone or in combination with short-acting insulin. However, the superiority of this approach over other insulin regimens has not been clearly established. Most patients with prednisolone-induced hyperglycaemia who are not already taking insulin should be prescribed a starting daily insulin dose of 0.5 units/ $\mathrm{kg}$. Patients on twice daily prednisolone or longer-acting glucocorticoids should be prescribed a basal insulin with a longer duration of action.

\section{Chronic low-dose glucocorticoid therapy}

\section{How commonly is low-dose prednisolone prescribed?}

Recent studies report the prevalence of long-term oral glucocorticoid use in the general population of the United Kingdom and United States is $0.75-1.2 \%(6,7)$. In clinical practice, glucocorticoids, usually prednisolone, are most commonly taken by patients with obstructive lung disease and inflammatory rheumatologic disorders, but are also prescribed for a wide range of other chronic inflammatory illnesses including gastrointestinal, dermatology, neurologic and renal disorders (6). The prevalence of glucocorticoid use increases with age, with up to $2.5 \%$ of adults aged $>60$ years prescribed longterm glucocorticoids (7). Consequently a large number of adults with other risk factors for diabetes (older age and an inflammatory illness) are prescribed chronic glucocorticoid therapy.

\section{Does long-term low-dose prednisolone increase blood glucose?}

As the effects of glucocorticoids on blood glucose concentration are dose dependent, (23) there has been uncertainty regarding the effects of chronic low-dose glucocorticoid therapy on blood glucose concentration. Most patients with inflammatory rheumatologic disease are prescribed daily prednisolone doses below $10 \mathrm{mg}$ (24). However, while these doses are much lower than those used acutely, they are substantially higher than average endogenous glucocorticoid production, which equates to about $3 \mathrm{mg}$ prednisolone per day (42).

We reported that patients on long-term lowdose prednisolone (4-10 mg/day) for inflammatory rheumatologic disease had no increase in fasting glucose concentration or glycosylated haemoglobin (HbA1c), but average glucose after a glucose load was increased by $1.2 \mathrm{mmol} / \mathrm{L}$ compared with patients with inflammatory arthritis who were not taking prednisolone (43). These results might be expected as low-dose prednisolone causes insulin resistance in liver and skeletal muscle (12, 44). However, they contrast another study reported that fasting and post glucose load glucose concentrations and insulin sensitivity in patients with rheumatoid arthritis were not affected by a similar prednisolone dose (45). This study did report that daily and cumulative prednisolone dose were associated with risk of diabetes (45). The patients in the study by Hoes et al. on prednisolone were 12 years younger and had a BMI that was $4 \mathrm{~kg} / \mathrm{m}^{2}$ less than prednisolone-treated patients in our study $(43,45)$. These differences in patient characteristics may influence susceptibility to the adverse metabolic effects of prednisolone. On balance, long-term prednisolone therapy at daily doses below $10 \mathrm{mg}$ causes mild postprandial hyperglycaemia, but minimal change in fasting glucose or HbA1c. The effects appear to be greater in older and overweight patients and in those with a higher cumulative prednisolone dose. 
How should you screen for diabetes in patients on long-term prednisolone?

In the general community, fasting glucose, an oral glucose tolerance test and $\mathrm{HbA1c}$ are all considered equally appropriate screening tests for type 2 diabetes (46). However, as prednisolone predominantly increases postprandial glucose, fasting glucose has low sensitivity to diagnose diabetes in this patient group. In patients with inflammatory rheumatologic disease, there is marked overlap in fasting glucose concentrations in patients with and without diabetes on long-term prednisolone, but much less so in patients not taking prednisolone (Fig. 3) (43). Average HbA1c is not increased, and it also has low sensitivity to diagnose diabetes in patients on long-term prednisolone (43). Consequently, the 2-h plasma glucose concentration during an oral glucose tolerance test identifies more cases of diabetes in patients on long-term prednisolone than fasting glucose or HbA1c (43). Some authors have proposed that a late afternoon random glucose should be used to screen for diabetes in patients taking prednisolone $(41,47)$. However, studies are needed to demonstrate the superiority of this approach.

\section{Is diagnosing prednisolone-induced diabetes important?}

The primary aim of treating hyperglycaemia in patients on long-term prednisolone is to reduce microvascular and macrovascular complications of diabetes. There are no data reporting rates of microvascular complications in patients on long-term prednisolone. HbA1c is a strong predictor of microvascular complications and average $\mathrm{HbA1c}$ is not increased by low-dose prednisolone $(43,48)$. However, other factors such as postprandial hyperglycaemia and glycaemic variability may also play an important role (49). Moreover, post-glucose load hyperglycaemia is associated with an increased risk of cardiovascular disease at glucose concentrations below the threshold for diabetes (50, 51). As inflammatory diseases per se are associated with increased cardiovascular risk (52), an important question is whether prednisolone-induced insulin resistance and consequent postprandial hyperglycaemia increases cardiovascular risk.

There are no clinical trials of sufficient size and duration to determine the effect of low-dose prednisolone on cardiovascular risk. Therefore, the cardiovascular effects of prednisolone can only be inferred from epidemiologic and mechanistic studies. Epidemiologic studies have reported that higher glucocorticoid doses

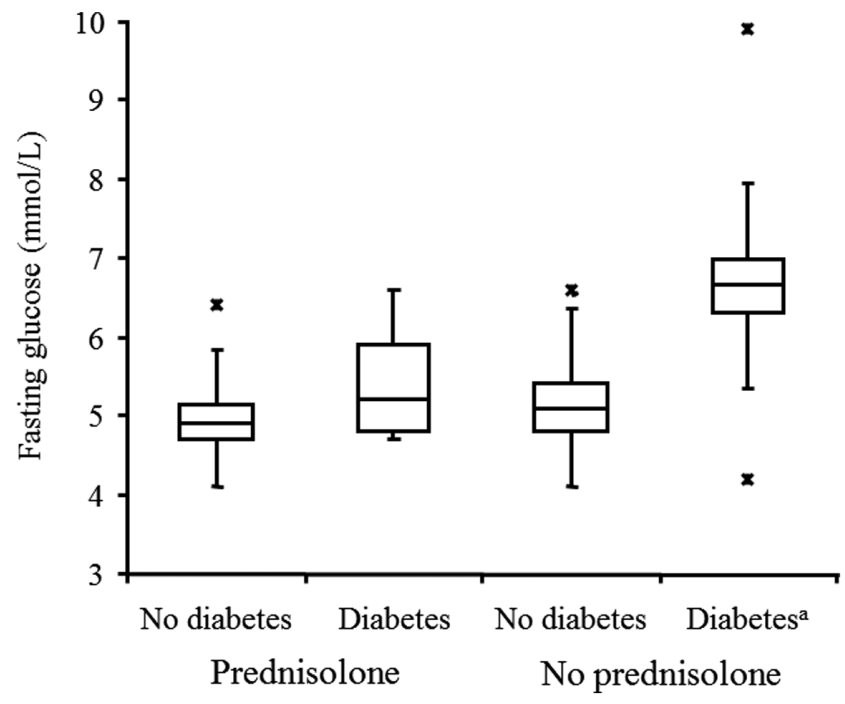

Figure 3

Box and whisker plots of fasting glucose concentration for subjects with and without diabetes receiving long-term prednisolone to treat an inflammatory rheumatologic disease and controls with an inflammatory rheumatologic disease who had not received oral glucocorticoids for at least 6 months. The box represents the median and interquartile range. The upper whisker extend upwards to 75th centile +1.5 * interquartile range or the maximum value, whichever is lower. The lower whisker extends downwards to the 25 th centile $-1.5^{*}$ the interquartile range or the minimum value, whichever is greater. $x$ denotes an outlier. ${ }^{a} P<0.0001$ vs other three groups. (Adapted from reference (43) with permission.)

increase all-cause and cardiovascular mortality $(9,53$, 54). Lower daily prednisolone doses below $10 \mathrm{mg}$ have been associated with increased mortality in some studies $(53,54)$, but not in others (9). Moreover, these studies are potentially confounded by indication bias.

Arterial stiffness and endothelial dysfunction are potential mechanisms by which glucocorticoids might increase cardiovascular risk, directly or indirectly via changes in insulin sensitivity and/or glucose levels. Arterial stiffness and endothelial dysfunction are strong predictors of cardiovascular risk, independent of other cardiovascular risk factors $(55,56)$ and are most strongly associated with post-glucose load glucose concentration $(57,58)$. Prednisolone reduces pulse wave velocity, the gold-standard measure of arterial stiffness, during an acute flare of an inflammatory illness (59), but in other clinical situations, glucocorticoids do not have a significant effect $(60,61,62)$. 
Glucocorticoid therapy has been associated with endothelial dysfunction in healthy adults (63), hypopituitary patients (60) and patients with IgA nephropathy (64). In contrast, in patients with inflammatory rheumatologic disease, long-term prednisolone has been reported to have a neutral or beneficial effect on fasting and postprandial endothelial function $(16,62,65)$. Plasma asymmetric dimethyl arginine is elevated in patients with rheumatoid arthritis who are not taking prednisolone, but not in patients on long-term low-dose prednisolone (66). If long-term prednisolone lowers the elevated levels of this endogenous nitric oxide synthase inhibitor, it could explain a beneficial effect of prednisolone on endothelial function in patients with inflammatory rheumatologic disease.

In summary, it is not clear to what extent lowdose prednisolone and the consequent minor increase in postprandial glucose increases cardiovascular risk. Moreover, the risks may vary in different patient populations. Pending further information, current thresholds for hypoglycaemic therapy and glycaemic targets should therefore be similar to those used in other clinical scenarios (67).

\section{How should prednisolone-induced diabetes be treated?}

There are few studies informing how to treathyperglycaemia in patients taking chronic low-dose prednisolone. Insulin is always a potential therapy, but will not be discussed further in this section. Many studies investigating the efficacy of other therapeutic agents have enrolled patients on moderate-to-high glucocorticoid doses, thereby potentially underestimating the glycaemic benefits in routine clinical practice where lower prednisolone doses are usually prescribed. As such, treatment decisions must be extrapolated from studies in patients with type 2 diabetes, along with an understanding of the pharmacodynamic effects and adverse drug reactions of prednisolone and hypoglycaemic therapy (Table 2). An ideal therapy will improve insulin sensitivity, target postprandial hyperglycaemia, not exacerbate the adverse drug reactions of prednisolone such as weight gain and increased fracture risk and reduce cardiovascular events in these patients who are at high baseline risk.

Metformin is first-line therapy in patients with type 2 diabetes and has a pharmacodynamic and side effect profile that recommends it as a therapeutic option in patients with prednisolone-induced hyperglycaemia. Metformin lowers fasting and postprandial blood glucose by increasing insulin sensitivity in the liver and effects mediated by the gastrointestinal tract $(68,69)$. In a small randomized controlled trial comprising 29 patients starting a mean daily prednisolone dose of $33 \mathrm{mg}$, metformin therapy for 4 weeks prevented the rise in plasma glucose associated with prednisone (70). As the effect of glucocorticoids on blood glucose is dose dependent, at lower glucocorticoid doses that are more commonly used long-term, metformin is likely to reduce blood glucose. As metformin does not increase weight and probably reduces cardiovascular and fracture risk $(71,72,73)$, it should not exacerbate other adverse effects associated with the underlying disease or long-term prednisolone.

Thiazolidinediones target two of the major metabolic abnormalities induced by glucocorticoids as they improve both hepatic and peripheral insulin sensitivity (74). Troglitazone was reported to be effective, but is now unavailable as it can cause hepatic failure (75). In a small study, pioglitazone improved glycaemic control in prednisone-treated patients after organ transplantation (76). However, pioglitazone is a less attractive therapeutic option in patients on prednisolone as its adverse effects such as weight gain, increased fracture risk and fluid retention mirror and potentially exacerbate the adverse effects of prednisolone $(73,74)$.

There is limited evidence that insulin secretagogues can be efficacious in patients on long-term glucocorticoids. The sulphonylurea glimepiride improved glycaemic control in three Japanese patients taking prednisolone 20-40 mg/day (77). However, the non-glycaemic effects of sulphonylureas are less favourable than metformin as they induce weight gain, can cause hypoglycaemia, have a neutral effect on fracture risk and uncertain effect on cardiovascular risk $(73,78)$. Meglitinides require multiple daily doses but have the potential advantages of predominantly affecting postprandial glucose and no weight gain (79). In a small open study, repaglinide provided effective glycaemic control in 14 of 23 patients on low-dose prednisolone combined with other immunosuppressive therapy (80).

Glucagon-like peptide-1 (GLP-1) analogues and dipeptidyl peptidase-4 (DPP-4) inhibitors predominantly lower postprandial glucose, suggesting they may be used to treat prednisolone-induced hyperglycaemia. Intravenous exenatide improved blood glucose in healthy subjects taking high-dose prednisolone for 2 days (81). However, apart from case reports (82), longer-term data on the efficacy of GLP-1 agonists in patients taking prednisolone is lacking. Liraglutide has not been studied in patients on prednisolone but its non-glycaemic effects 
Table 2 Effects of prednisolone and glucose-lowering treatments on weight, and fracture and cardiovascular risk.

\begin{tabular}{|c|c|c|c|c|c|c|c|}
\hline & Prednisolone & Metformin & Sulphonylureas & Thiazoledinediones & GLP-1 agonists & DPP-4 inhibitors & SGLT2 inhibitors \\
\hline Weight & $\uparrow$ & $\leftrightarrow$ & $\uparrow$ & $\uparrow$ & $\downarrow$ & $\leftrightarrow$ & $\downarrow$ \\
\hline Fracture risk & $\uparrow$ & $\downarrow$ & $\leftrightarrow$ & $\uparrow$ & $\uparrow / \leftrightarrow / \downarrow *$ & $\leftrightarrow / \downarrow *$ & $\uparrow$ \\
\hline $\begin{array}{l}\text { Cardiovascular } \\
\text { risk }\end{array}$ & $\uparrow / \downarrow *$ & $\downarrow$ & $\leftrightarrow$ & $\uparrow / \downarrow^{*}$ & $\downarrow$ & $\leftrightarrow$ & $\downarrow$ \\
\hline
\end{tabular}

* May vary in different patient populations or for different drugs in class (see text for details).

$\uparrow$, increased; $\downarrow$, reduced; $\leftrightarrow$, unchanged; DPP-4, dipeptidyl peptidase-4; GLP-1, glucagon-like peptide-1; SGLT2, sodium-glucose co-transporter-2.

are favourable as it can cause weight loss and reduce fracture and cardiovascular risk $(73,83)$. In contrast, some data suggest exenatide may increase fracture risk (73). The DPP-4 inhibitor sitagliptin improved glycaemic control in a retrospective study of subjects on low-dose prednisolone (84), but did not attenuate the postprandial effects of a $30 \mathrm{mg}$ daily prednisolone dose in a prospective randomized controlled trial (85). These contrasting results may reflect the difference in prednisolone dose in the two studies or could reflect potential selection bias in the retrospective study. DPP-4 inhibitors do not exacerbate the side effects of prednisolone.

Finally, sodium-glucose co-transporter-2 (SGLT2) inhibitors also predominantly reduce postprandial glucose in patients with type 2 diabetes. However, dapaglifozin did not improve glycaemic control in patients with type 2 diabetes or hyperglycaemia while taking high dose prednisolone (86). SGLT2 inhibitors reduce weight and cardiovascular mortality in patients with type 2 diabetes, but may increase fracture risk $(73,87)$.

\section{Summary}

Long-term low-dose prednisolone causes a small increase in post glucose-load glucose concentration, but no change in fasting glucose or HbA1c. Patients should be screened for prednisolone-induced diabetes with an oral glucose tolerance test. It is unclear whether prednisoloneinduced elevations in postprandial glucose are associated with increased cardiovascular risk, particularly in patients with inflammatory rheumatologic disease. While there are small studies, treatment of hyperglycaemia in patients on long-term low-dose prednisolone generally requires extrapolation of clinical effects of hypoglycaemic therapies in patients with type 2 diabetes and consideration of the adverse effect profile of prednisolone and hypoglycaemic agents. Metformin has prospective randomized controlled trial evidence supporting its efficacy and does not exacerbate the potential adverse effects of prednisolone and is a suggested first-line therapy in outpatients taking long-term low-dose prednisolone.

\section{Future directions and final conclusions}

After almost 70 years of using glucocorticoids to treat inflammatory disease, there are many unanswered questions regarding how to treat glucocorticoid-induced hyperglycaemia. Identification of factors underlying the variability in response to insulin therapy in hospitalized patients with hyperglycaemia while taking glucocorticoids is needed to inform individualized treatment and improve patient management. In outpatients taking long-term low-dose prednisolone, further understanding of the cardiovascular risk associated with postprandial hyperglycaemia and studies of the effects of hypoglycaemic therapies in patients on lower doses of prednisolone are needed to provide a stronger evidence base to manage this large group of patients. Based on the current limited evidence, we advocate first-line therapy for hyperglycaemia with isophane-based basal bolus insulin regimens in hospitalized patients treated with acute prednisolone and metformin in outpatients taking chronic low-dose prednisolone.

Declaration of interest

Dr M G Burt has previously received grant funding from the Novo Nordisk Regional Diabetes Scheme.

\section{Funding}

$\operatorname{Dr}$ A Radhakutty is supported by a National Health Medical Research Council, Australia Postgraduate Research Scholarship.

\section{References}

1 Hench PS, Kendall EC, Slocumb CH \& Polley HF. The effect of a hormone of the adrenal cortex (17-hydroxy11-dehydrocorticosterone: compound E) and of pituitary adrenocorticotropic hormone on rheumatoid arthritis. Proceedings of the Staff Meetings of the Mayo Clinic 194924 181-197.

2 Kirwan JR, Balint G \& Szebenyi B. Anniversary: 50 years of glucocorticoid treatment in rheumatoid arthritis. Rheumatology 1999 38 100-102. (https://doi.org/10.1093/rheumatology/38.2.100)

3 Strehl C \& Buttgereit F. Optimized glucocorticoid therapy: teaching old drugs new tricks. Molecular and Cellular Endocrinology 2013380 32-40. (https://doi.org/10.1016/j.mce.2013.01.026) 
4 Benard-Laribiere A, Pariente A, Pambrun E, Begaud B, Fardet L \& Noize P. Prevalence and prescription patterns of oral glucocorticoids in adults: a retrospective cross-sectional and cohort analysis in France. BMJ Open 20177 e015905. (https://doi.org/10.1136/ bmjopen-2017-015905)

5 Ward LE, Polley HF, Slocumb CH \& Hench PS. Cortisone in treatment of rheumatoid arthritis. JAMA $1953 \mathbf{1 5 2}$ 119-126. (https://doi. org/10.1001/jama.1953.03690020011003)

6 Fardet L, Petersen I \& Nazareth I. Prevalence of long-term oral glucocorticoid prescriptions in UK over the past 20 years. Rheumatology 201150 1982-1990.

7 Overman RA, Yeh JY \& Deal CL. Prevalence of oral glucocorticoid usage in the United States: a general population perspective. Arthritis Care and Research 201365 294-298. (https://doi.org/10.1002/acr.21796)

8 Fong AC \& Cheung NW. The high incidence of steroid-induced hyperglycaemia in hospital. Diabetes Research and Clinical Practice 201399 277-280. (https://doi.org/10.1016/j.diabres.2012.12.023)

9 Wei L, MacDonald TM \& Walker BR. Taking glucocorticoids by prescription is associated with subsequent cardiovascular disease. Annals of Internal Medicine 2004141 764-770. (https://doi. org/10.7326/0003-4819-141-10-200411160-00007)

10 Rizza RA, Mandarino LJ \& Gerich JE. Cortisol-induced insulin resistance in man: impaired suppression of glucose production and stimulation of glucose utilization due to a postreceptor detect of insulin action. Journal of Clinical Endocrinology and Metabolism 1982 54 131-138. (https://doi.org/10.1210/jcem-54-1-131)

11 Tappy L, Randin D, Vollenweider P, Vollenweider L, Paquot N, Scherrer U, Schneiter P, Nicod P \& Jequier E. Mechanisms of dexamethasone-induced insulin resistance in healthy humans. Journal of Clinical Endocrinology and Metabolism 199479 1063-1069.

12 Petersons CJ, Mangelsdorf BL, Jenkins AB, Poljak A, Smith MD, Greenfield JR, Thompson CH \& Burt MG. Effects of low-dose prednisolone on hepatic and peripheral insulin sensitivity, insulin secretion, and abdominal adiposity in patients with inflammatory rheumatologic disease. Diabetes Care 201336 2822-2829. (https:// doi.org/10.2337/dc12-2617)

13 Henriksen JE, Alford F, Vaag A, Handberg A \& Beck-Nielsen H. Intracellular skeletal muscle glucose metabolism is differentially altered by dexamethasone treatment of normoglycemic relatives of type 2 diabetic patients. Metabolism 199948 1128-1135. (https://doi. org/10.1016/S0026-0495(99)90126-9)

14 Dirlewanger M, Schneiter PH, Paquot N, Jequier E, Rey V \& Tappy L. Effects of glucocorticoids on hepatic sensitivity to insulin and glucagon in man. Clinical Nutrition 200019 29-34. (https://doi. org/10.1054/clnu.1999.0064)

15 van Raalte DH, Nofrate V, Bunck MC, van Iersel T, Elassaiss Schaap J, Nassander UK, Heine RJ, Mari A, Dokter WH \& Diamant M. Acute and 2-week exposure to prednisolone impair different aspects of beta-cell function in healthy men. European Journal of Endocrinology 2010162 729-735. (https://doi.org/10.1530/EJE-09-1034)

16 Radhakutty A, Mangelsdorf BL, Drake SM, Samocha-Bonet D, Jenkins AB, Heilbronn LK, Smith MD, Thompson CH \& Burt MG. Effect of acute and chronic glucocorticoid therapy on insulin sensitivity and postprandial vascular function. Clinical Endocrinology 201684 501-508. (https://doi.org/10.1111/cen.12966)

17 Eriksen M, Jensen DH, Tribler S, Holst JJ, Madsbad S \& Krarup T. Reduction of insulinotropic properties of GLP-1 and GIP after glucocorticoid-induced insulin resistance. Diabetologia $2015 \mathbf{5 8}$ 920-928. (https://doi.org/10.1007/s00125-015-3522-y)

18 Burt MG, Roberts GW, Aguilar-Loza NR, Frith P \& Stranks SN. Continuous monitoring of circadian glycemic patterns in patients receiving prednisolone for COPD. Journal of Clinical Endocrinology and Metabolism 201196 1789-1796.

19 Yuen KC, McDaniel PA \& Riddle MC. Twenty-four-hour profiles of plasma glucose, insulin, C-peptide and free fatty acid in subjects with varying degrees of glucose tolerance following short-term, medium- dose prednisone $(20 \mathrm{mg} /$ day) treatment: evidence for differing effects on insulin secretion and action. Clinical Endocrinology 201277 224-232. (https://doi.org/10.1111/j.1365-2265.2011.04242.x)

20 Donihi AC, Raval D, Saul M, Korytkowski MT \& DeVita MA. Prevalence and predictors of corticosteroid-related hyperglycemia in hospitalized patients. Endocrine Practice 200612 358-362. (https:// doi.org/10.4158/EP.12.4.358)

21 Darmon P, Dadoun F, Boullu-Ciocca S, Grino M, Alessi MC \& Dutour A. Insulin resistance induced by hydrocortisone is increased in patients with abdominal obesity. American Journal of Physiology: Endocrinology and Metabolism 2006291 E995-E1002. (https://doi. org/10.1152/ajpcell.00238.2006)

22 Henriksen JE, Alford F, Ward GM \& Beck-Nielsen H. Risk and mechanism of dexamethasone-induced deterioration of glucose tolerance in non-diabetic first-degree relatives of NIDDM patients. Diabetologia 199740 1439-1448. (https://doi.org/10.1007/ s001250050847)

23 Matsumoto K, Yamasaki H, Akazawa S, Sakamaki H, Ishibashi M, Abiru N, Uotani S, Matsuo H, Yamaguchi Y, Tokuyama K et al. Highdose but not low-dose dexamethasone impairs glucose tolerance by inducing compensatory failure of pancreatic beta-cells in normal men. Journal of Clinical Endocrinology and Metabolism $1996 \mathbf{8 1}$ 2621-2626.

24 Gurwitz JH, Bohn RL, Glynn RJ, Monane M, Mogun H \& Avorn J. Glucocorticoids and the risk for initiation of hypoglycemic therapy. Archives of Internal Medicine 1994154 97-101. (https://doi. org/10.1001/archinte.1994.00420010131015)

25 Umpierrez GE, Hellman R, Korytkowski MT, Kosiborod M, Maynard GA, Montori VM, Seley JJ \& Van den Berghe G. Management of hyperglycemia in hospitalized patients in noncritical care setting: an Endocrine Society Clinical Practice Guideline. Journal of Clinical Endocrinology and Metabolism 201297 16-38. (https://doi.org/10.1210/jc.2011-2098)

26 Popovic M, Blum CA, Nigro N, Mueller B, Schuetz P \& ChristCrain M. Benefit of adjunct corticosteroids for community-acquired pneumonia in diabetic patients. Diabetologia 201659 2552-2560. (https://doi.org/10.1007/s00125-016-4091-4)

27 Umpierrez GE, Isaacs SD, Bazargan N, You X, Thaler LM \& Kitabchi AE. Hyperglycemia: an independent marker of in-hospital mortality in patients with undiagnosed diabetes. Journal of Clinical Endocrinology and Metabolism 200287 978-982. (https://doi.org/10.1210/jcem.87.3.8341)

28 Umpierrez GE, Smiley D, Jacobs S, Peng L, Temponi A, Mulligan P, Umpierrez D, Newton C, Olson D \& Rizzo M. Randomized study of basal-bolus insulin therapy in the inpatient management of patients with type 2 diabetes undergoing general surgery (RABBIT 2 Surgery). Diabetes Care 201134 256-261. (https://doi.org/10.2337/dc10-1407)

29 Ceriello A, Esposito K, Piconi L, Ihnat MA, Thorpe JE, Testa R, Boemi M \& Giugliano D. Oscillating glucose is more deleterious to endothelial function and oxidative stress than mean glucose in normal and type 2 diabetic patients. Diabetes 200857 1349-1354. (https://doi.org/10.2337/db08-0063)

30 Radhakutty A, Stranks JL, Mangelsdorf BL, Drake SM, Roberts GW, Zimmermann AT, Stranks SN, Thompson CH \& Burt MG. Treatment of prednisolone-induced hyperglycaemia in hospitalized patients: insights from a randomized, controlled study. Diabetes, Obesity and Metabolism 201719 571-578. (https://doi.org/10.1111/dom.12859)

31 Burt MG, Drake SM, Aguilar-Loza NR, Esterman A, Stranks SN \& Roberts GW. Efficacy of a basal bolus insulin protocol to treat prednisolone-induced hyperglycaemia in hospitalised patients. Internal Medicine Journal 201545 261-266. (https://doi.org/10.1111/imj.12680)

32 Gosmanov AR, Goorha S, Stelts S, Peng L \& Umpierrez GE. Management of hyperglycemia in diabetic patients with hematologic malignancies during dexamethasone therapy. Endocrine Practice 2013 19 231-235. (https://doi.org/10.4158/EP12256.OR)

33 Umpierrez GE, Smiley D, Zisman A, Prieto LM, Palacio A, Ceron M, Puig A \& Mejia R. Randomized study of basal-bolus insulin therapy 
in the inpatient management of patients with type 2 diabetes (RABBIT 2 trial). Diabetes Care 200730 2181-2186. (https://doi. org/10.2337/dc07-0295)

34 Roberts GW, Aguilar-Loza NR, Esterman A, Burt MG \& Stranks SN. Basal-bolus insulin and sliding scale insulin for inpatient glycaemic management of patients with type 2 diabetes - a clinical practicebased comparison. Medical Journal of Australia 2012196 266-269. (https://doi.org/10.5694/mja11.10853)

35 Magee MH, Blum RA, Lates CD \& Jusko WJ. Pharmacokinetic/ pharmacodynamic model for prednisolone inhibition of whole blood lymphocyte proliferation. British Journal of Clinical Pharmacology 2002 53 474-484. (https://doi.org/10.1046/j.1365-2125.2002.01567.x)

36 Clore JN \& Thurby-Hay L. Glucocorticoid-induced hyperglycemia. Endocrine Practice 200915 469-474. (https://doi.org/10.4158/ EP08331.RAR)

37 Dhital SM, Shenker Y, Meredith M \& Davis DB. A retrospective study comparing neutral protamine hagedorn insulin with glargine as basal therapy in prednisone-associated diabetes mellitus in hospitalized patients. Endocrine Practice 201218 712-719. (https:// doi.org/10.4158/EP11371.OR)

38 Grommesh B, Lausch MJ, Vannelli AJ, Mullen DM, Bergenstal RM, Richter SA \& Fish LH. Hospital insulin protocol aims for glucose control in glucocorticoid-induced hyperglycemia. Endocrine Practice 201622 180-189. (https://doi.org/10.4158/EP15818.OR)

39 Ruiz de Adana MS, Colomo N, Maldonado-Araque C, Fontalba MI, Linares F, Garcia-Torres F, Fernandez R, Bautista C, Olveira G, de la Cruz JL et al. Randomized clinical trial of the efficacy and safety of insulin glargine vs NPH insulin as basal insulin for the treatment of glucocorticoid induced hyperglycemia using continuous glucose monitoring in hospitalized patients with type 2 diabetes and respiratory disease. Diabetes Research and Clinical Practice 2015110 158-165. (https://doi.org/10.1016/j.diabres.2015.09.015)

40 Yates CJ, Fourlanos S, Colman PG \& Cohney SJ. Divided dosing reduces prednisolone-induced hyperglycaemia and glycaemic variability: a randomized trial after kidney transplantation. Nephrology Dialysis Transplantation 201429 698-705. (https://doi. org/10.1093/ndt/gft377)

41 Perez A, Jansen-Chaparro S, Saigi I, Bernal-Lopez MR, Minambres I \& Gomez-Huelgas R. Glucocorticoid-induced hyperglycemia. Journal of Diabetes 20146 9-20. (https://doi.org/10.1111/1753-0407.12090)

42 Esteban NV, Loughlin T, Yergey AL, Zawadzki JK, Booth JD, Winterer JC \& Loriaux DL. Daily cortisol production rate in man determined by stable isotope dilution/mass spectrometry. Journal of Clinical Endocrinology and Metabolism 199172 39-45. (https://doi. org/10.1210/jcem-72-1-39)

43 Burt MG, Willenberg VM, Petersons CJ, Smith MD, Ahern MJ \& Stranks SN. Screening for diabetes in patients with inflammatory rheumatological disease administered long-term prednisolone: a cross-sectional study. Rheumatology 201251 1112-1119. (https://doi. org/10.1093/rheumatology/kes003)

44 van Raalte DH, Brands M, van der Zijl NJ, Muskiet MH, Pouwels PJ, Ackermans MT, Sauerwein HP, Serlie MJ \& Diamant M. Low-dose glucocorticoid treatment affects multiple aspects of intermediary metabolism in healthy humans: a randomised controlled trial. Diabetologia 201154 2103-2112. (https://doi.org/10.1007/s00125011-2174-9)

45 Hoes JN, van der Goes MC, van Raalte DH, van der Zijl NJ, den Uyl D, Lems WF, Lafeber FP, Jacobs JW, Welsing PM, Diamant M et al. Glucose tolerance, insulin sensitivity and \{beta\}-cell function in patients with rheumatoid arthritis treated with or without low-tomedium dose glucocorticoids. Annals of the Rheumatic Diseases 2011 70 1887-1894.

46 American Diabetes Association. 2. Classification and diagnosis of diabetes: standards of medical care in diabetes-2018. Diabetes Care 201841 S13-S27.
47 Suh S \& Park MK. Glucocorticoid-induced diabetes mellitus: an important but overlooked problem. Endocrinology and Metabolism 201732 180-189. (https://doi.org/10.3803/EnM.2017.32.2.180)

48 Nathan DM, McGee P, Steffes MW, Lachin JM \& Group DER. Relationship of glycated albumin to blood glucose and HbA1c values and to retinopathy, nephropathy, and cardiovascular outcomes in the DCCT/EDIC study. Diabetes 201463 282-290. (https://doi. org/10.2337/db13-0782)

49 Cavalot F. Do data in the literature indicate that glycaemic variability is a clinical problem? Glycaemic variability and vascular complications of diabetes. Diabetes, Obesity and Metabolism 201315 (Supplement 2) 3-8. (https://doi.org/10.1111/dom.12140)

50 Barrett-Connor E \& Ferrara A. Isolated postchallenge hyperglycemia and the risk of fatal cardiovascular disease in older women and men. The Rancho Bernardo Study. Diabetes Care 199821 1236-1239. (https://doi.org/10.2337/diacare.21.8.1236)

51 DECODE Study Group tEDEG. Glucose tolerance and cardiovascular mortality: comparison of fasting and 2-hour diagnostic criteria. Archives of Internal Medicine 2001161 397-405.

52 Steen KS, Lems WF, Visman IM, Heierman M, Dijkmans BA, Twisk JW, Boers M \& Nurmohamed MT. High incidence of cardiovascular events in patients with rheumatoid arthritis. Annals of the Rheumatic Diseases 200968 1509-1510. (https://doi.org/10.1136/ ard.2008.105023)

53 Souverein PC, Berard A, Van Staa TP, Cooper C, Egberts AC, Leufkens HG \& Walker BR. Use of oral glucocorticoids and risk of cardiovascular and cerebrovascular disease in a population based case-control study. Heart 200490 859-865. (https://doi.org/10.1136/ hrt.2003.020180)

54 Listing J, Kekow J, Manger B, Burmester GR, Pattloch D, Zink A $\&$ Strangfeld A. Mortality in rheumatoid arthritis: the impact of disease activity, treatment with glucocorticoids, TNFalpha inhibitors and rituximab. Annals of the Rheumatic Diseases 201574 415-421. (https://doi.org/10.1136/annrheumdis-2013-204021)

55 Vlachopoulos C, Aznaouridis K \& Stefanadis C. Prediction of cardiovascular events and all-cause mortality with arterial stiffness: a systematic review and meta-analysis. Journal of the American College of Cardiology 201055 1318-1327. (https://doi.org/10.1016/j. jacc.2009.10.061)

56 Matsuzawa Y, Sugiyama S, Sumida H, Sugamura K, Nozaki T, Ohba K, Matsubara J, Kurokawa H, Fujisue K, Konishi M et al. Peripheral endothelial function and cardiovascular events in high-risk patients. Journal of the American Heart Association 20132 e000426. (https://doi. org/10.1161/JAHA.113.000426)

$57 \mathrm{Li}$ CH, Wu JS, Yang YC, Shih CC, Lu FH \& Chang CJ. Increased arterial stiffness in subjects with impaired glucose tolerance and newly diagnosed diabetes but not isolated impaired fasting glucose. Journal of Clinical Endocrinology and Metabolism 201297 E658-E662. (https://doi.org/10.1210/jc.2011-2595)

58 Crandall JP, Shamoon H, Cohen HW, Reid M, Gajavelli S, Trandafirescu G, Tabatabaie V \& Barzilai N. Post-challenge hyperglycemia in older adults is associated with increased cardiovascular risk profile. Journal of Clinical Endocrinology and Metabolism 200994 1595-1601.

59 Schillaci G, Bartoloni E, Pucci G, Pirro M, Settimi L, Alunno A, Gerli R \& Mannarino E. Aortic stiffness is increased in polymyalgia rheumatica and improves after steroid treatment. Annals of the Rheumatic Diseases 201271 1151-1156. (https://doi.org/10.1136/ annrheumdis-2011-200751)

60 Petersons CJ, Mangelsdorf BL, Thompson CH \& Burt MG. Acute effect of increasing glucocorticoid replacement dose on cardiovascular risk and insulin sensitivity in patients with adrenocorticotrophin deficiency. Journal of Clinical Endocrinology and Metabolism 201499 2269-2276. (https://doi.org/10.1210/jc.20134305) 
61 Tanaka K, Inaba M, Goto H, Nagata-Sakurai M, Sakai S, Yamada S, Ueda M, Ishimura E \& Nishizawa Y. Paraarticular trabecular bone loss at the ultradistal radius and increased arterial stiffening in postmenopausal patients with rheumatoid arthritis. Journal of Rheumatology 200633 652-658.

62 Petersons CJ, Mangelsdorf BL, Poljak A, Smith MD, Greenfield JR, Thompson $\mathrm{CH} \&$ Burt MG. Low dose prednisolone and insulin sensitivity differentially affect arterial stiffness and endothelial function: an open interventional and cross-sectional study. Atherosclerosis 2017258 34-39. (https://doi.org/10.1016/j. atherosclerosis.2017.01.033)

63 van Raalte DH, Diamant M, Ouwens DM, Ijzerman RG, Linssen MM, Guigas B, Eringa EC \& Serne EH. Glucocorticoid treatment impairs microvascular function in healthy men in association with its adverse effects on glucose metabolism and blood pressure: a randomised controlled trial. Diabetologia 201356 2383-2391. (https://doi.org/10.1007/s00125-013-3016-8)

64 Uchida HA, Nakamura Y, Kaihara M, Norii H, Hanayama Y, Sugiyama H, Maeshima Y, Yamasaki Y \& Makino H. Steroid pulse therapy impaired endothelial function while increasing plasma high molecule adiponectin concentration in patients with IgA nephropathy. Nephrology Dialysis Transplantation 200621 3475-3480. (https://doi.org/10.1093/ndt/gfl423)

65 Hafstrom I, Rohani M, Deneberg S, Wornert M, Jogestrand T \& Frostegard J. Effects of low-dose prednisolone on endothelial function, atherosclerosis, and traditional risk factors for atherosclerosis in patients with rheumatoid arthritis - a randomized study. Journal of Rheumatology 200734 1810-1816.

66 Radhakutty A, Mangelsdorf BL, Drake SM, Rowland A, Smith MD, Mangoni AA, Thompson CH \& Burt MG. Opposing effects of rheumatoid arthritis and low dose prednisolone on arginine metabolomics. Atherosclerosis 2017266 190-195. (https://doi. org/10.1016/j.atherosclerosis.2017.10.004)

67 American Diabetes Association. 6. Glycemic targets: standards of medical care in diabetes-2018. Diabetes Care 201841 S55-S64.

68 Inzucchi SE, Maggs DG, Spollett GR, Page SL, Rife FS, Walton V $\&$ Shulman GI. Efficacy and metabolic effects of metformin and troglitazone in type II diabetes mellitus. New England Journal of Medicine 1998338 867-872. (https://doi.org/10.1056/NEJM199803263381303)

69 DeFronzo RA, Buse JB, Kim T, Burns C, Skare S, Baron A \& Fineman M. Once-daily delayed-release metformin lowers plasma glucose and enhances fasting and postprandial GLP-1 and PYY: results from two randomised trials. Diabetologia 201659 1645-1654. (https://doi.org/10.1007/s00125-016-3992-6)

70 Seelig E, Meyer S, Timper K, Nigro N, Bally M, Pernicova I, Schuetz P, Muller B, Korbonits M \& Christ-Crain M. Metformin prevents metabolic side effects during systemic glucocorticoid treatment. European Journal of Endocrinology 2017176 349-358. (https://doi. org/10.1530/EJE-16-0653)

71 UK Prospective Diabetes Study (UKPDS) Group. Effect of intensive blood-glucose control with metformin on complications in overweight patients with type 2 diabetes (UKPDS 34). Lancet 1998352 854-865.

72 Holman RR, Paul SK, Bethel MA, Matthews DR \& Neil HA. 10-year follow-up of intensive glucose control in type 2 diabetes. New England Journal of Medicine 2008359 1577-1589. (https://doi. org/10.1056/NEJMoa0806470)

73 Meier C, Schwartz AV, Egger A \& Lecka-Czernik B. Effects of diabetes drugs on the skeleton. Bone 201682 93-100. (https://doi. org/10.1016/j.bone.2015.04.026)

74 Yki-Jarvinen H. Thiazolidinediones. New England Journal of Medicine 2004351 1106-1118. (https://doi.org/10.1056/NEJMra041001)
75 Willi SM, Kennedy A, Brant BP, Wallace P, Rogers NL \& Garvey WT. Effective use of thiazolidinediones for the treatment of glucocorticoid-induced diabetes. Diabetes Research and Clinical Practice 200258 87-96. (https://doi.org/10.1016/S01688227(02)00127-4)

76 Luther P \& Baldwin D Jr. Pioglitazone in the management of diabetes mellitus after transplantation. American Journal of Transplantation 20044 2135-2138. (https://doi.org/10.1111/j.16006143.2004.00613.x)

77 Kasayama S, Tanaka T, Hashimoto K, Koga M \& Kawase I. Efficacy of glimepiride for the treatment of diabetes occurring during glucocorticoid therapy. Diabetes Care 200225 2359-2360. (https:// doi.org/10.2337/diacare.25.12.2359)

78 Ferrannini E \& DeFronzo RA. Impact of glucose-lowering drugs on cardiovascular disease in type 2 diabetes. European Heart Journal 2015 36 2288-2296. (https://doi.org/10.1093/eurheartj/ehv239)

79 Dornhorst A. Insulinotropic meglitinide analogues. Lancet 2001358 1709-1716. (https://doi.org/10.1016/S01406736(01)06715-0)

80 Turk T, Pietruck F, Dolff S, Kribben A, Janssen OE, Mann K, Philipp T, Heemann U \& Witzke O. Repaglinide in the management of newonset diabetes mellitus after renal transplantation. American Journal of Transplantation 20066 842-846. (https://doi.org/10.1111/j.16006143.2006.01250.x)

81 van Raalte DH, van Genugten RE, Linssen MM, Ouwens DM \& Diamant M. Glucagon-like peptide-1 receptor agonist treatment prevents glucocorticoid-induced glucose intolerance and islet-cell dysfunction in humans. Diabetes Care 201134 412-417. (https://doi. org/10.2337/dc10-1677)

82 Matsuo K, Nambu T, Matsuda Y, Kanai Y, Yonemitsu S, Muro S $\&$ Oki S. Evaluation of the effects of exenatide administration in patients with type 2 diabetes with worsened glycemic control caused by glucocorticoid therapy. Internal Medicine 201352 89-95. (https:// doi.org/10.2169/internalmedicine.52.8622)

83 Marso SP, Daniels GH, Brown-Frandsen K, Kristensen P, Mann JF, Nauck MA, Nissen SE, Pocock S, Poulter NR, Ravn LS et al. Liraglutide and cardiovascular outcomes in type 2 diabetes. New England Journal of Medicine 2016375 311-322. (https://doi.org/10.1056/ NEJMoa1603827)

84 Katsuyama H, Sako A, Adachi H, Hamasaki H \& Yanai H. Effects of 6-month sitagliptin treatment on metabolic parameters in diabetic patients taking oral glucocorticoids: a retrospective cohort study. Journal of Clinical Medicine Research 20157 479-484. (https://doi. org/10.14740/jocmr2153w)

85 van Genugten RE, van Raalte DH, Muskiet MH, Heymans MW, Pouwels PJ, Ouwens DM, Mari A \& Diamant M. Does dipeptidyl peptidase-4 inhibition prevent the diabetogenic effects of glucocorticoids in men with the metabolic syndrome? A randomized controlled trial. European Journal of Endocrinology 2014170 429-439. (https://doi.org/10.1530/EJE-13-0610)

86 Gerards MC, Venema GE, Patberg KW, Kross M, Potter van Loon BJ, Hageman IMG, Snijders D, Brandjes DPM, Hoekstra JBL, Vriesendorp TM et al. Dapagliflozin for prednisone-induced hyperglycaemia in acute exacerbation of chronic obstructive pulmonary disease. Diabetes, Obesity and Metabolism 201820 1306-1310. (https://doi.org/10.1111/dom.13209)

87 Zinman B, Wanner C, Lachin JM, Fitchett D, Bluhmki E, Hantel S, Mattheus M, Devins T, Johansen OE, Woerle HJ et al. Empagliflozin, cardiovascular outcomes, and mortality in type 2 diabetes. New England Journal of Medicine 2015373 2117-2128. (https://doi. org/10.1056/NEJMoa1504720)

Received 13 April 2018

Revised version received 17 June 2018

Accepted 6 July 2018 